\title{
GROWTH AND DEVELOPMENT OF ROOTED PLANTLETS OF BACOPA MONNIERI L. IN AUXIN-FREE TISSUE CULTURE MEDIUM
}

ANITA MEHTA

Department of Botany, Ranchi Women' S College, Ranchi, India

Indefinite number of platelets of Bacopa monnieri were regenerated from field grown shoot apex explants when implanted on auxin-free Murashige and Skoog (MS) medium supplemented with different cytokines (BA or KN), growth adjuvant adenine sulfate (AdS) and a small amount of citric acid. It was observed that when BA (or BAP) alone was used for multiplication of shoot apex/ bud explants, the proliferated shoots exhibited slower and stunted growth accompanied with abscission of leaves and shoot tip necrosis (STN). The problem of leaf abscission and STN was considerably reduced by the application of AdS and citric acid in the BA (or BAP) supplemented medium which led to the production of maximum 10 platelets with mean shoot length of $8.5 \mathrm{~cm}$ per culture within two months. There were no visible morphological abnormalities observed in the micropropagated plantlets. The formation of abnormal callus-like growth or tumors or tissue proliferation at the base of the elongated stem was observed which affected rooting competence of the elongated shoots. Tissue culture is an extraordinary stressful treatment of the plant tissue, which induces the production of phenolic compounds in the medium. It seems the root stimulating efficiency of various phenolic compounds and their relationship with auxins which enhance rooting even in auxin-free medium. Two and half months old in vitro grown plantlets were transferred to polyglasses containing sterile coco peat for acclimatization. Survival rate was observed $100 \%$ when acclimatized plantlets were transferred to soil.

KEYWORDS: BAP, AdS, Citric Acid, Shoot-Tip Necrosis \& Phenolic Compounds
\end{abstract}

Received: Apr 07, 2017; Accepted: May 09, 2017; Published: May 25, 2017; Paper Id.: IJBRJUN20172

\section{INTRODUCTION}

In a priority list of the most important medicinal plants, evaluated on the basis of their medical importance, commercial value and potential for further research and development, Bacopa monnieri L. (Family: Scrophulariaceae, commonly known as Brahmi) was placed second, according to a sector study by the Exportimport Bank of India (1). According to an estimate the annual requirement of the plant was projected to be about- 12,700 tonnes of dry material, valued of approximately Rs 15 billion (2). Many medicinal plant species with their proactive molecules are disappearing at an alarming rate due to rapid agriculture and urban development, uncontrolled deforestation and indiscriminate collection by the plant-based pharmaceutical companies. Therefore, there is an immediate need of conservation of each and every medicinal plant before it becomes extinct. Plant tissue culture is the methodology for ex-situ conservation of important flora with immense potentialities of crop improvement. The best commercial application of plant tissue technique has been in the production of true to type plants as well as variants also. In recent years regeneration of plants from callus produced during tissue culture show considerable variations, with characters of economic importance such as resistance, male sterility, enhancement of secondary metabolite in callus culture (3). Earlier efforts have already been made by the author to study micropropagation of Bacopa monnieri where occurrence of callus formations was a regular phenomena (4) 
(5) whereas during current work plant growth regulators used in the media are quite different.

Moreover, plant tissue technique is an integral part of the genetic transformation process and production of secondary metabolite. (6)

The present investigation has been carried out with an objective to obtain a rapid multiplication of platelets only without callus growth.

\section{MATERIALS AND METHODS}

Collection of Plant Materials

3 Months old plants of Bacopa monnieri were collected from the garden of Dr S.K. Aggarwalla, (MBBS doctor and Herbal practitioner), Amrita Family Health Center, Lalpur Ranchi and get it authenticated from the Laboratory of Plant Taxonomy Ethnobotany and Medicinal Plants; in-charge Prof. Kunul Kandir Univ, Dept. of Botany Ranchi Univ. Young and juvenile shoot apex/buds, were used for explants preparation.

\section{Surface Sterilization}

10-15 cm platelets with 8-10 nodes were washed in running tap water to remove the dust particles adhering to the surface followed by 15 min treatment with $0.1 \%$ bavistin, a fungicide. This was followed by three washes with distilled water to remove the traces of fungicide. Finally platelets were treated with $0.1 \% \mathrm{HgCl}_{2}$ in a laminar air flow cabinet which was followed by three washes with autoclaved distilled water to remove the traces of $\mathrm{HgCl}_{2}$. Now the sterilized platelets were cut into pieces and $1.0-1.5 \mathrm{~cm}$ shoot apex/buds were used for inoculation.

\section{Culture Media}

For the establishment of cultures Murashige and Skoog (7) basal culture media containing 3\% w/v sucrose as carbon source was used. Before gelling with Difco-bacto agar $(0.8 \% \mathrm{~W} / \mathrm{V}) \mathrm{pH}$ of the media was adjusted to 5.8. Desired concentration of cytokines (benzyle amino purine BAP; or Kinetin KN), growth adjuvant (adenine sulfate AdS) and citric acid (an anti-oxidant) was added in hot and homogenized semi solid medium. About 50ml hot medium was poured into each culture bottle (300 ml lug neck bottles with polypropylene caps) which were washed, rinsed and oven-dried thoroughly. Culture bottles containing media were autoclaved for $15-20 \mathrm{~min}$. At a pressure of $1.06 \mathrm{Kg} / \mathrm{cm}^{2}\left(120^{\circ} \mathrm{c}\right)$ and were kept in the inoculation room.

\section{Culture Condition}

After implantation of the explants (mainly shoot apex/buds) cultures were incubated at $20 \pm 5^{\circ} \mathrm{c}$ under cool fluorescent light (1500-2000 Lux) with a 16/8 hours light/dark period and 65\% of relative humidity.

\section{Establishment of Culture and Subculturing}

During present investigation, generally shoot apex/ buds were inoculated on MS media with different plant growth regulators by varying concentration. The growth response of exploits was recorded every week. Each experiment with a minimum of 10 cultures was repeated thrice and maintained in the culture cabinets. For optimum shoot multiplication best plant growth regulator concentration was selected on the basis of number of shoots/per explant. After 50 days of interval elongated platelets, thus obtained were cut into pieces and again shoot apex was subcultured onto fresh medium with the same compassion for further multiplication. 


\section{Planting Out and Acclimatization}

Some micropropagated plantlets were kept for drying for phytochemical studies while some were washed gently under running tap water and transferred to plastic pots containing a potting mixture (autoclaved coco peat mixture) for acclimatization. Platelets were nourished with half strength MS nutrient solution on a daily basis. During the acclimatization control of temperature and humidity was achieved by covering the transplanted plantlets with transparent plastic covers with holes and keeping the pots under shade.

After 40-50 days of initial transplanting the individual plantlets were transferred to larger plastic pots containing garden soil, farmyard manure and coco peat in equal proportion. The platelets are ready for transfer in the garden soil by about $1 \frac{1}{2}$ month and $100 \%$ transplantation success was observed with morphologically similar features.

\section{RESULTS AND OBSERVATIONS}

During the present investigation short-apex/bud was inoculated for platelet formation with varying concentration of BAP (Benzyl amino purine). Bud break was achieved within 10 days in MS media supplemented with 1 mg/l BAP but the proliferated shoots exhibited slower and stunted growth accompanied with abscission of leaves and shoot tip necrosis (STN) (Figure 5,6). This effect was continued with increasing chance. Of BAP. During current work these problems of STN and leaf abscission was considerably reduced by the application of an adjuvant, adenine sulfate (Ads) in the optimal medium which led to the production of maximum 10 shoots in each bottle.

Therefore a further improvement in shoot bud regeneration and improved growth pattern of the regenerating tissue was obtained on the medium comprised of MS+BAP (1mg/l) +AdS (50mg/l). During present work it was also observed that further addition of citric acid in the above medium resulted in the formation of rooted plantlets (Figure 1,2,3,4). After a period of 6 weeks these micropropagated in vitro grown plantlets were subsequently dissected into exploits and sub cultures on fresh MS medium without varying the combination and concentration of plant growth regulator, growth adjuvants and citric acid. These $2^{1 / 2}$ months old (after subculture) micropropagated plantlets were the best suited plants for planting out, acclimatization and for transferring to the soil. The $100 \%$ survival rate was observed in the soil. These micropropogated platelets were also used for pre-washing, shade drying and for grinding for powder making for different phytochemical studies.

Due to STN the development of basal callus like growth was also observed and therefore production of some phenolic substances in the culture medium cannot be ignored.

During the present investigation one unusual phenomenon was observed that was the emergence of root system without the addition of any rooting hormone.

\section{DISCUSSIONS}

The development of tissue culture protocol is a rigorous procedure that involves optimizing the various chemicals, physical and environmental factors of growth. It involves growing plants outside their natural environment and growth condition which require a series of experiments and practices. During micropropagation practices, problems arise related to developmental and physiological aspects such as shoot- tip necrosis (8) fascinations (9) tissue proliferation (10) epigenetic changes 11somaclonal variation (12) effect of phenolics on rooting (13) alleviating problems related to cryogenic and resurgence processes (14) etc. 
During the present investigation occurrence of STN cannot be ignored, which was inhibited by addition of AdS. Similar results were found in the case of Syzygium cumini while studying the effect of AdS on growth and development under in vitro conditions (15) Naaz A. et al. 2014). Therefore BAP and AdS, grown micropropagated plantlets were successfully acclimatized and transferred under field condition with a $100 \%$ survival rate. The limited rooting ability of tissue cultured plant is an important factor challenging the use of tissue culture. After Thimann and Went (16) (1934) remarked that auxins promote adventitious rooting, several discoveries were made on the aspects of rooting. These discoveries range from isolating new rooting hormones (natural and synthetic) two ways of enhancing their activities.

In this current work, it seems there is a root stimulating efficiency of various phenolic compounds and their relationship with auxins. Similar type of result was observed by (13) while working role of phenolics on rooting of slices of apple microshoots, because the first response to the stress in the plant is the production of phenolic compounds, so there must be some substance in the media which can imbibe it. It does not seem to harm the plants at all, however, it does definitely affect root growth. Tissue culture is an extraordinary stressful treatment of the plant tissue, regardless of whether full nutrition is provided or not. Excision, osmoticum, hormones, etc. are treatments used during tissue culture that can cause severe stress. It is well known that wounding, pathogen, drought, salt, cold and a number of other stresses induce the pathways that produce phenolic compounds in plant. So the specific combination of stress factors in tissue culture condition (culture medium, light, temp, etc.) and the species/ exploits being cultured, result in production of phenolics while others do not. (17). Being an important group of secondary metabolite phenolics may act as modulators of plant development by regulating endogenous/exogenous IAA catabolism (18)

\section{ACKNOWLEDGEMENT}

Author is thankful to Dr G. Srinivas, Joint Secretary University Grant Commission, Eastern Regional Office, Kolkata, for providing financial support as Minor Research Project. Author is also thankful to Dr. Madhupurna Banerjee, College of Biotechnology, Birsa Agricultural University, Kanke.
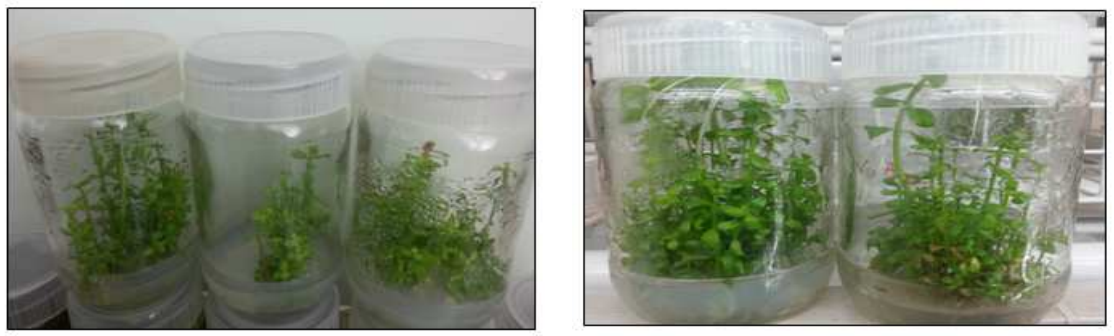

Figure 1,2: Shoot Apex/Bud Culture on MS+BAP(1mg/l)+AdS (50mg/l)+Citric Acid (1 mg/l) Showing Well Developed Plantlets of Bacopa Monneiri
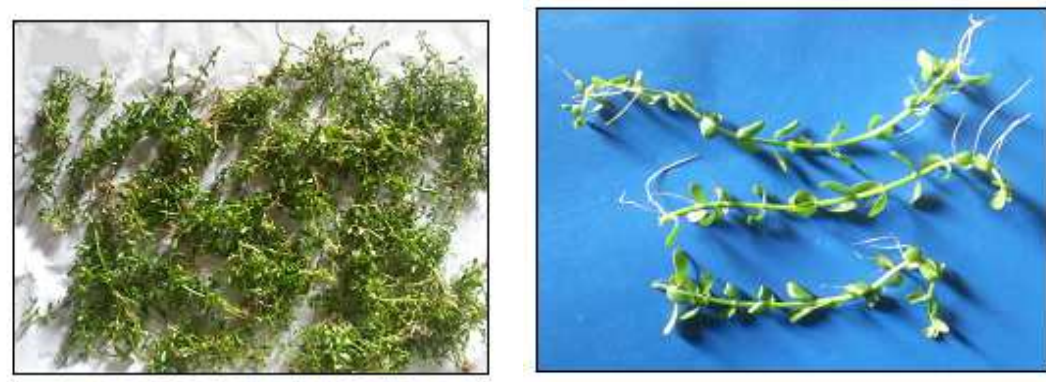

Figure 3, 4: Micropropagated Plantlets of Bacopa Monneiri 


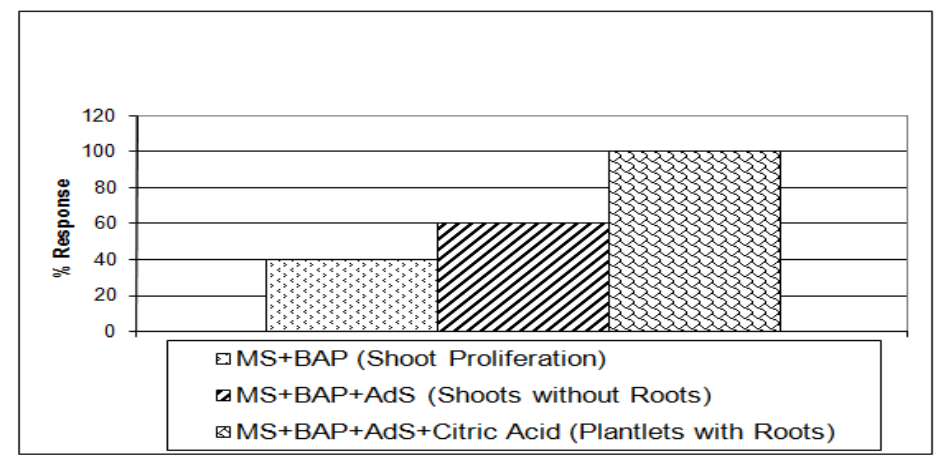

Figure 5: Percentage of Growth and Development of Plantlets of Bacopa Monnieri in Ms Media with Different Growth Suppliments

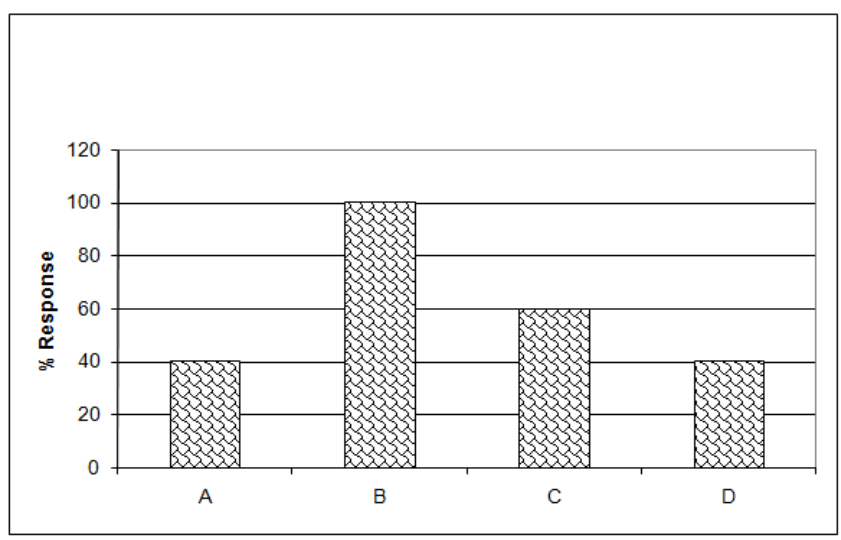

Figure 6: Percentage of Growth and Development of Plantlets of Bacopa Monnieri in Ms Media with Different Concentration of Growth Supplements

$$
\begin{aligned}
& \mathrm{A}=\mathrm{MS}+\mathrm{BAP}(0.5 \mathrm{mg} / \mathrm{l})+\operatorname{AdS}(20 \mathrm{mg} / \mathrm{l})+\text { Citric Acid }(0.5 \mathrm{mg} / \mathrm{l} \\
& \mathrm{B}=\mathrm{MS}+\mathrm{BAP}(1 \mathrm{mg} / \mathrm{l})+\operatorname{AdS}(50 \mathrm{mg} / \mathrm{l})+\text { Citric Acid}(1 \mathrm{mg} / \mathrm{l}) \\
& \mathrm{C}=\mathrm{MS}+\mathrm{BAP}(2 \mathrm{mg} / \mathrm{l})+\operatorname{AdS}(75 \mathrm{mg} / \mathrm{l})+\text { Citric Acid}(1.5 \mathrm{mg} / \mathrm{l}) \\
& \mathrm{D}=\mathrm{MS}+\mathrm{BAP}(2.5 \mathrm{mg} / \mathrm{l})+\operatorname{AdS}(100 \mathrm{mg} / \mathrm{l})+\text { Citric Acid}(2 \mathrm{mg} / \mathrm{l})
\end{aligned}
$$

\section{REFERENCES}

1. Export-import Bank of India (1997). Indian Medicinal Plants: A Sector Study. Occasional paper No. 54, 2. Quest Publication, Bombay, India.

2. Ahmad RU (1993). Medicinal Plants used in ISM- Their procurement, cultivation, regeneration and import/export aspets: A Report. In: Govil JN, Singh VK, Hashmi S (eds) Medicinal Plants: New Vistas of Research (Part1). Today Tomorrow Printers and Publishers, New Delhi, pp 221-225.

3. Scala, A., Bettini, P., Buiatti, M., Bogani, P., Pellegrini, G. and Tognoni, F., 1984. In vitro analysis of the tomato-fusarium oxysporum system and selection experiments. In: F.J. Novak et al. (Eds.), Plant Tissue and Cell Culture Application to Crop Improvement. Czechoslovak Acad. Sci., Prague, pp.361-362. Hammerschlag, F.A. and Ognjanov, V., 1990. Somaclonal variation in peach: screening for resistance to Xanthomonas campestris pv. pruni and Pseudomonas syringae pv. syringae. Acta Hortic., 280:403-408. Mariani, C., De Beuckeleer, M., Truettner, J., Leemans, J. and Goldberg, R.B., 1990. Induction of male sterility in plants by chimeric ribonuclease-inhibitor gene. Nature, 347:737-741. 
4. Mehta A. Purak I. Pandey R.K. (2008). Studies on High regeneration potentiality of Brahmi(Bacopa monnieri L.) in in vitro cullure. The Bioscan 3(4):501-504

5. Mehta A., Singh A., Purak I. (2009). In vitro multiplication of plantlets of Bacopa monnieri L. and their ex-vitro growth. Vegetos 22(1):11-16

6. Majumdar, Garai S., Jha S. et at. (2012). Role of cryptogein gene to stimulate the accumulation of Bacopa saponins in transgenic Bacopa monnieri plants. Plant cell Reports 31(10):1899-1909

7. Murarhighe T. \& skoog F. (1962). A revised medium for rapid growth and bioassay with tobacco tissue culture. Physiol plant. $15,473-497$

8. Bairu MW, Stirk WA, Van staden J (2009). Factors contributing to in vitro shoot-tip necrosis and their physiological interactions. Plant cell tissue organ culture 98:239-248 Bairu MW, Novak O, Dolezal K., Van Staden J (2011). Changesendogenous cytokinin profiles in micro propagated Harpagophytum procumbens in retation to shoot-tip necrosis and cytokinin treatment. Plant Growth Regul.63(2):105-114 Bairu MW, Kane ME (2011): Physiological and developmental problems encountered by in vitro cultured plants. Plant Growth Regul. 63(2):101-103

9. Iliev I, Kitin P (2011). Origin, morphology and anatomy of fasciation in plants cultured in vivo and in vitro. Plant Growth Regul.63(2):115-129

10. Brand MH (2011). Tissue proliferation condition in micro propagated ericaceous plants- Plant Growth Regul. 63(2):131-136

11. Smulders MJM, Klerk GJ de (2011). Epigenetics in plant tissue culture. Plant Growth Regul. 63(2):137-146

12. Bairu MW, Aremu AO, Van Staden J (2011). Somaclonal variation in plants: causes and detection methods. Plant Growth Regul. 63(2):147-173

13. De Klerk GJ, Guan H, Huisman P, Marinova S (2011). Effects of phenolic compounds on adventitions root formations and oxidative decarboxylation of applied indoleacetic acid in Malus 'Jork 9'. Plant Growth Regul. 63(2):175-185

14. Moyo M, Finnie JF, Van Staden J(2011). Recalcitrant effects- associated with the development of basal callus-like tissue on caulogenesis and rhizogenesis in sclerocarya birrea. Plant Growth Regul. 63(2):187-195

15. Naaz A, Shahzad A, Anis M. (2014). Effect of adenine sulphate interaction on growth and development of shoot regeneration and inhibition of shoot tip necrosis under in vitro condition in adult Syzygium cumini L.- a multipurpose tree. Appl. Biochem Biotechnol 173(1): 90-102.

16. Thimann $K V$, Went FW (1934). On the chemical nature of the root-forming hormone. Pro Kon Akad Wetensch 37:456-459.

17. Popular answer from Research Gate.

18. Arnaldos TL, Munoz R, Ferrer MA. Calderon AA (2001). Changes in phenol content during strawberry callus culture. Physiol Plant. 113: 315-322 